\title{
Simultaneous Quantification of Bioactive Triterpene acids (Ursolic acid and Oleanolic acid) in Different Extracts of Eucalyptus globulus (L) by HPTLC Method
}

\author{
Arti Gupta ${ }^{1 *}$, Pooja Maheta ${ }^{1}$, Renu Chauhann ${ }^{1}$, Sonia Pandey', Jitendra Singh Yadav ${ }^{2}$, Shailesh Shah ${ }^{1}$
}

\section{Arti Gupta ${ }^{1 *}$, Pooja Maheta', Renu Chauhan', Sonia Pandey ${ }^{1}$, Jitendra Singh Yadav $^{2}$, Shailesh Shah ${ }^{1}$}

'Maliba Pharmacy College, Bardoli, 394350, Gujarat, INDIA.

${ }^{2}$ Shree Naranjibhai Lalbhai Patel College of Pharmacy, Umrakh, 394345, Gujarat, INDIA.

Correspondence

Dr. Arti Gupta

Maliba Pharmacy College, Bardoli, 394350, Gujarat, INDIA.

Phone no: 9558848242

E-mail: aarti137@rediffmail.com

\section{History}

- Submission Date: 05-08-2017;

- Review completed: 31-08-2017;

- Accepted Date: 20-11-2017

DOI : 10.5530/pj.2018.1.30

Article Available online

http://www.phcogj.com/v10/i1

\section{Copyright}

(C) 2018 Phcog.Net. This is an openaccess article distributed under the terms of the Creative Commons Attribution 4.0

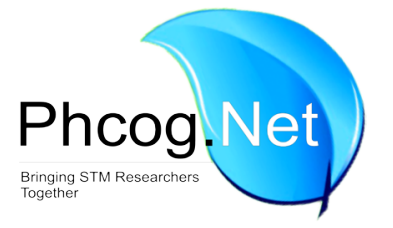

\begin{abstract}
Objective: To develop a novel analytical method for simultaneous determination of two triterpenic acids by high-performance thin layer chromatography in methanol and dichloromethane extracts of Eucalyptus globulus leaf. Ursolic acid was also isolated from Eucalyptus globulus leaf. Materials and Methods: Two triterpenic acids (ursolic and oleanolic acid) were extracted using methanol and dichloromethane as the extraction solvents. Study for total triterpenoids present in Eucalyptus globulus leaves was carried out which shows considerable amount of terpenoids present. Because of the similarity of chemical structure, the prechromatographic derivatization was necessary to separate these triterpenic acids. The samples were treated by $1 \%$ iodine solution in chloroform directly on the chromatographic plate and developed with the mobile phase consisting of petroleum ether, ethyl acetate and acetone (7.8:2.2:0.1, v/v/v). After drying, the plates were sprayed with $10 \%(\mathrm{v} / \mathrm{v})$ ethanol solution of sulfuric acid and heated to $120^{\circ} \mathrm{C}$ for $3 \mathrm{~min}$. Quantification was performed in absorbance/transmittance mode at a wavelength of $345 \mathrm{~nm}$. The developed HPTLC method was validated for linearity, precision and accuracy. Results: Correlation coefficient $\left(r^{2}>0.99\right)$, R.S.D. values, detection limits as well as recovery values were found to be satisfactory. Ursolic acid was isolated from E. globulus leaves. The identification of isolated ursolic acid was done on the basis of Rf value (0.26) for HPTLC and peak interpretation for FT-IR. Conclusion: The method has been successfully applied in the analysis of both triterpenic acids in medicinal herbs.
\end{abstract}

Key words: Ursolic acid, Oleanolic acid, HPTLC, lodine derivatization, Triterpenes.

\section{INTRODUCTION}

Triterpenoids are an interesting group of compounds in nature. Oleanolic acid and ursolic acid are triterpenoid compounds that exist widely in food, medicinal herbs and other plants. ${ }^{1}$ Ursolic acid (3-hydroxy-urs-12-en28-oic acid) and its isomer, oleanolic acid (3-hydroxyolea-12-en-28-oic acid) are bioactive compounds with confirmed pharmacological properties. In recent years they became the subject of many publications because of their various activities combined with low toxicity. ${ }^{2}$ Eucalyptus spp. (family Myrtaceae) originated in Australia, but these plants now grow in almost all tropical and sub-tropical areas and are cultivated in many other climates. Much research has been conducted on the medicinal properties of Eucalyptus spp. The leaf extract or essential oil from the leaves of Eucalyptus spp. has been reported to possess antifungal, antibacterial, mosquito repellent and antioxidant properties. ${ }^{3}$ In the case of Eucalyptus spp., it has been reported that the lipophilic extracts of E. globulus outer bark contain high amounts of several triterpenic acids with ursane and oleanane skeletons, namely ursolic and oleanolic acids. ${ }^{4}$ These triterpenic acids are recognized as promising compounds for the development of new oleanolic and ursolic acids show significant antiinflammatory, ${ }^{9-16}$ anticancer, ${ }^{17}$ Anti-Platelet Aggregation, ${ }^{18-19}$ Anti-HIV/AIDS, ${ }^{20-21}$ Anti-Mycobaterium Tuberculosis, ${ }^{22-27}$ anti-proliferative ${ }^{28}$ and hepatoprotective ${ }^{29-31}$ properties in laboratory animals.

Literature describes HPLC ${ }^{31,32-42}$ HPTLC $^{43-47}$ micellar electrokinetic chromatography (MEC) ${ }^{48-49}$ and Thin-layer chromatography has been also described methods for analysis of ursolic acid and oleanolic acid alone as well as simultaneously from other plants and extracts but oleanolic and ursolic acids are position isomers are shown in Figure.1 and their separation by TLC is rather difficult. There are some chromatographic systems to determine these triterpenic acids reported in literature but none of them enable their separation in eucalyptus leaves. On the other hand, modern TLC is powerful analytical technique, especially useful to analysis of plant material because large number of samples can be chromatographed simultaneously and the samples without any pretreatment can be applied. In case of compounds multi-targeting bioactive agents ${ }^{5-8}$ For example,

Cite this article: Gupta A, Maheta P, Chauhan R, Pandey S, Yadav JS, Shah S. Simultaneous quantification of bioactive triterpene acids (ursolic acid and oleanolic acid) in different extracts of Eucalyptus globulus (L) by HPTLC Method. Pharmacog J. 2018;10(1):179-85. 
with similar chemical structure, sometimes the pre-chromatographic derivatization can be helpful in their determination. There are a lot of examples of use the specific chemical derivatization, for example, esterification was employed in analysis of primary, secondary and tertiary alcohols and hydrolysis (acidic or alkaline) were used in determination of flavonoids, triterpenes and cardenolide glycosides. ${ }^{50}$

However, there is no published report describing separation of ursolic acid and oleanolic acid from methanolic and DCM extracts of Eucalyptus globulus leaves. The yield of the lipophilic extractives of bark extracted with dichloromethane was good with previous results of E. globulus ${ }^{4}$ that's why DCM was selected for further study.

Pre-chromatographic derivatization was required because of chemical structural similarity of ursolic acid and oleanolic acid. HPTLC is a wellknown and versatile separation method which shows a lot of advantages in comparison to other separation techniques. HPTLC is the simplest separation technique today available to the analyst. HPTLC layer is more homogeneous and thinner resulting in improved resolution, shorter analysis time and suitable for in situ quantification.

\section{MATERIALS AND METHODS}

\section{Apparatus}

HPTLC system (Linomat 5, Camag, Switzerland) automatic sample applicator, TLC scanner IV (Camag), flat bottom and twin- trough developing chamber (15 X $10 \mathrm{~cm})$, Darmstadt, Germany), pre-coated silica gel, aluminum plate (E. Merck, electronic, analytical balance, Shimadzu (AUX-220), micro syringe (100 ml) (Hamilton).

\section{Reagents and standard}

Ursolic acid and Oeanolic acid were purchased from Yucca enterprises, Wadala, Mumbai and methanol AR grade from S.d. fine-Chem Ltd., Mumbai.

\section{Standard and sample preparation}

Stock solutions of ursolic acid and oleanolic acid were prepared by dissolving $10 \mathrm{mg}$ of each compound in $100 \mathrm{~mL}$ of methanol (final concentration $1000 \mu \mathrm{g} / \mathrm{ml}$ ). Standard concentration of $20 \mu \mathrm{g} / \mathrm{ml}$ of both compounds were prepared by dilution of stock solutions with methanol. To quantification $15 \mathrm{gm}$ of dry powdered leaves of eucalyptus globulus were extracted with methanol and dichloromethane for $7 \mathrm{hrs}$ in soxhlet apparatus. The obtained extracts were evaporated to dryness and $10 \mathrm{mg}$ residue was dissolved in $10 \mathrm{ml}$ methanol separately, which were further diluted to get $100 \mu \mathrm{g} / \mathrm{ml}$ concentration.

\section{Estimation of total triterpenoids by colorimetric method}

Accurately measured quantity of plant extracts were dissolved in $25 \mathrm{ml}$ of ethanol. A volume of $0.2 \mathrm{ml}$ of ethanol solution was transferred in a graduated test tube and it was evaporated to dryness in a boiling water bath. A volume of $0.3 \mathrm{ml}$ of $5 \%$ vanillin/glacial acetic acid and $1 \mathrm{ml}$ of perchloric acid solution were added. The sample solutions were heated at $60^{\circ} \mathrm{C}$ for $45 \mathrm{~min}$ and cooled in an ice water bath to the ambient temperature. A volume $5 \mathrm{ml}$ of glacial acetic acid was added. The absorbance of the samples was measured at $548 \mathrm{~nm}$. The same procedure was repeated for preparation of standard ursolic acid. The percentage of total triterpenoids was calculated from the calibration curve. ${ }^{51}$

\section{Estimation of UA in DCM extracts}

Accurately weighed 5.0 gm samples in $25 \mathrm{ml} 50 \% \mathrm{v} / \mathrm{v}$ methanol, was heated to ensure complete dissolution. A volume of $75 \mathrm{ml}$ water was added and mixed thoroughly. It was transferred to a $250 \mathrm{ml} \mathrm{RBF}$ and $10 \mathrm{gm} \mathrm{H}_{2} \mathrm{SO}_{4}$ was zadded and refluxed 6-8 hr. The contents were cooled \& transferred into separating funnel. About $25 \mathrm{ml}$ chloroform was added, shaken for a while \& allowed to stand for layer separation. The chloroform layer was transferred to another separator and aq. Acidic layer once again washed with $25 \mathrm{ml}$ chloroform. The separated chloroform layer was mixed with earlier washing. Both chloroform washings $(50 \mathrm{ml})$ were washed with water till acid free (2-3 washing). Acid free chloroform layer was dried over anhydrous sodium sulphate and after filtration; chloroform is evaporated to dryness in a pre-weighed beaker. The residue in beaker was finally dried at $80^{\circ} \mathrm{C}$ under vacuum to constant weight. This gives the quality of total triterpinic acids for calculating the percentage of ursolic acid. ${ }^{52}$

\section{Chromatographic conditions}

In simultaneous estimation pre-coated silica gel $60 \mathrm{~F}_{254}$ aluminium plates of $10 \times 10 \mathrm{~cm}$ and $20 \times 10 \mathrm{~cm}$ (Merck, Germany) were used as stationary phase.

Twenty five micro litres of mixture of standard solutions, $20 \mu \mathrm{L}$ of both methanolic and DCM extracts solutions were spotted using an Linomat V semiautomatic sample applicator (Camag, Switzerland) under nitrogen at $6 \mathrm{~mm}$ band length and $15 \mathrm{~mm}$ distance from left edge and from bottom and $10 \mathrm{~mm}$ distance from centres of tracks.

\section{Prechromatographic derivatization}

The plates were developed in glass chamber with $1 \%$ iodine solution in chloroform to a $1.5 \mathrm{~cm}$, plate was removed and the start zone was covered by aluminium foil and the plates were placed in dark for 10 minutes. When the reaction was complete, the plates were dried in a stream of warm air to remove the excess of iodine.

\section{Chromatography and determination}

The pre-derivatized plates were developed with a mixture of Petroleum ether : ethyl acetate : acetone $(7.8: 2.2: 0.2)(\mathrm{v} / \mathrm{v} / \mathrm{v})$ as mobile phase on a distance of $7.5 \mathrm{~cm}$. after drying in a stream of warm air the plates were sprayed with $10 \%(\mathrm{v} / \mathrm{v}) \mathrm{H}_{2} \mathrm{SO}_{4}$ in ethanol, dried for $10 \mathrm{~min}$ and then heated to $110^{\circ} \mathrm{C}$ for $5 \mathrm{~min}$.

The quantification was carried out by densitometric scanning (Camag TLC scanner IV) at absorbance transmittance at $\lambda=345 \mathrm{~nm}$ (slit distance: $4.00 \times 0.30 \mathrm{~mm}$ )

Derivatization and determination were performed under controlled conditions at room temperature $\left(27 \pm 2^{\circ} \mathrm{C}\right)$

\section{RESULTS AND DISCUSSION}

The \% yields obtained with methanolic and DCM extracts from E. globulus are recorded $10 \%$ and $47 \%(\mathrm{w} / \mathrm{w})$ respectively. The lipophilic fractions of plants were shown to be mainly composed of triterpenic compounds. ${ }^{4}$

Total terpenoids estimation by calorimetric method (method 1) shows that methanolic and DCM extracts contain $45 \pm 5 \%(450 \mathrm{mg} / \mathrm{gm})$ and $80 \pm 5 \%(795 \mathrm{mg} / \mathrm{gm})$ terpenoids respectively.

Total terpenoid estimation from extract by (method 2$)$ shows that methanolic and DCM extracts contain $52 \pm 5 \%(0.52 \mathrm{gm} / \mathrm{gm})$ and $84 \pm 5(0.84$ $\mathrm{gm} / \mathrm{gm}$ ) terpenoids respectively.

Drugs were characterized by determination of Melting point of ursolic acid and oleanolic acid, that are showing $288 \pm 2^{\circ} \mathrm{C}$ and $298 \pm 2^{\circ} \mathrm{C}$ respectively. UA and OA both show reasonably good absorbance at $345 \mathrm{~nm}$. Therefore $345 \mathrm{~nm}$ was selected as detection wavelength for both standards for HPTLC. The mobile phase petroleum ether: ethyl acetate: acetone (7.8:2.2:0.2 $\mathrm{v} / \mathrm{v} / \mathrm{v})$ gave good separation, compact spot, good resolution with $\mathrm{R}_{\mathrm{f}} 0.24$ and 0.40 for UA and OA, respectively. 
With optimized mobile phase composition and saturation time, the drugs Ursolic acid and Oleanolic acid showed Rf value 0.24 and 0.40 , respectively.

\section{Simultaneouse estimation of UA and OA in DCM and Methanolic extracts}

Densitogram of ursolic acid [(200ng/spot); $(\mathrm{Rf}=0.24)]$, oleanolic acid (200 ng/spot); $(\mathrm{Rf}=0.40)]$ and the mixture of both standards in DCM and methanolic extract [(200 ng/spot) ( $\mathrm{Rf}=0.24$ for UA and 0.40 for $\mathrm{OA})$ ] were shown in Figure $2 \mathrm{~A}, \mathrm{~B}$ and $\mathrm{C}$ ).

Densitogram of DCM extract was shown in figure 2D, having six peaks, the fourth peak Rf value $(0.25)$ and fifth peak Rf value $(0.39)$ were coinciding with standard Rf values of ursolic acid and oleanolic acid respectively. The concentration of ursolic acid and oleanolic in DCM extract of E. globulus were found to be $174.57 \mathrm{ng} / \mathrm{spot}$ and $146.30 \mathrm{ng} / \mathrm{spot}$. Densitogram of methanolic extract was shown in Figure $2 \mathrm{E}$ having four peaks, $\mathrm{Rf}(0.25)$ value of fourth peak was coinciding with standard $\mathrm{Rf}$ value of ursolic acid. The concentration of ursolic acid in methanolic extract of E. globulus was found to be $97.59 \mathrm{ng} / \mathrm{spot}$.

\section{Method validation}

The presented method was validated for linearity, specificity, precision, accuracy and Calibration curve was prepared using mixed working standard solution in the range of 100-500 $\mathrm{ng} / \mathrm{spot}$ for both Ursolic acid and Oleanolic acid. The 3D chromatogram is shown in Figure 3. The
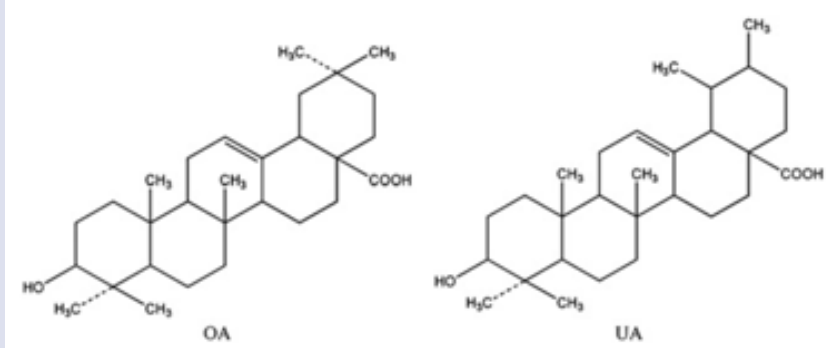

Figure 1: Chemical structures of oleanolic acid and ursolic acid.

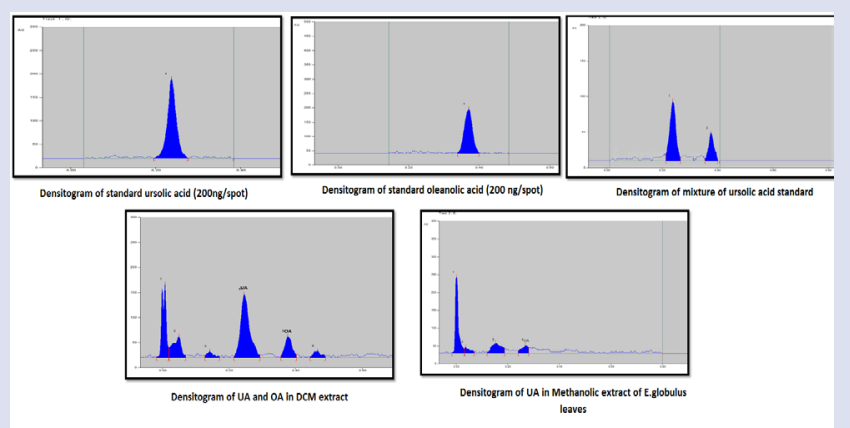

Figure 2: Densitogram of (A) Standard ursolic acid, (B) Standard oleanolic acid, (C) Mixture of standard ursolic and oleanolic acid, (D) DCM extract and (E) Methanolic extract.

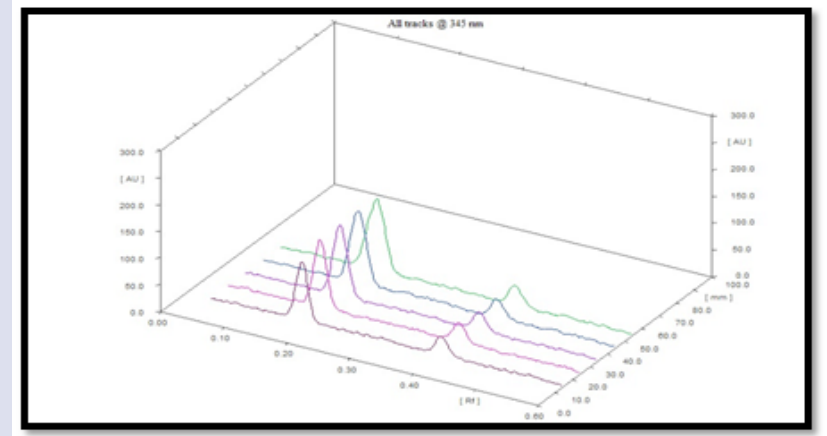

Figure 3: 3D densitogram of ursolic and oleanolic acid (100-500 ng/spot).

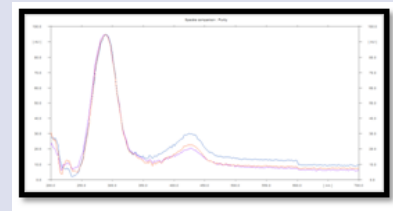

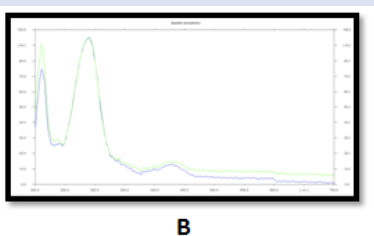

B
Figure 4: An Overlain spectra of standard ursolic acid and ursolic acid present in DCM and methanolic extracts, B Overlain spectra of standard oleanolic acid and oleanolic acid present in DCM extract.

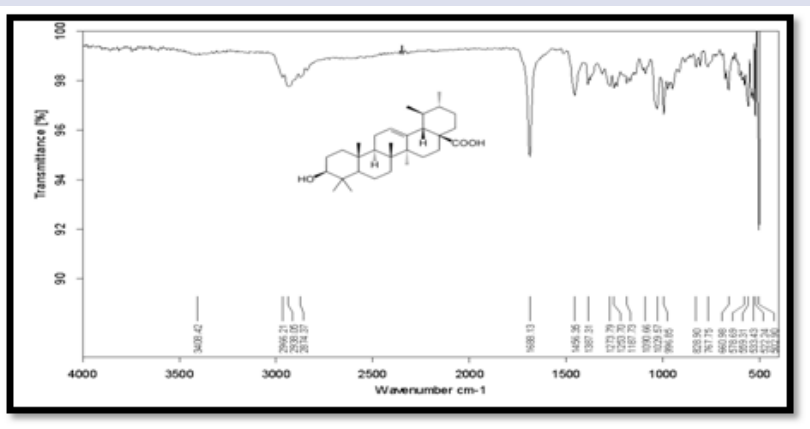

Figure 5: Reported FT-IR spectra of standard ursolic acid.

other component present in extract did not interfere in the separation and resolution of UA and OA. Both UA and OA were found to be linear in the above-mentioned range with correlation coefficient of 0.9954 and 0.9937 , respectively. The average linear regression equations for calibration curves were $\mathrm{y}=3.397 \mathrm{x}+586.18$ and $\mathrm{y}=2.8602 \mathrm{x}-199.5$ for UA and OA, respectively. Linearity data and its summary are depicted in Table 1. Comparison of each spectrum scanned at peak start (s), peak apex (m) and peak end (e) positions of bands in samples showed a high degree of correlation (above 0.99), confirmed the purity of the bands are presented in Figure 4 which confirm that the method is specific.

For precision of method, repeatability of sample application and measurement and interday and intraday precision was measured. The data for repeatability and Intermediate precision of measurement and 


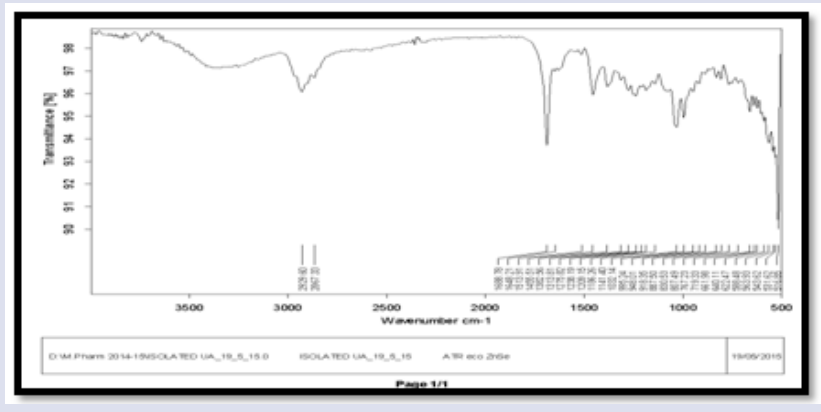

Figure 6: Observed FT-IR spectra of isolated ursolic acid.

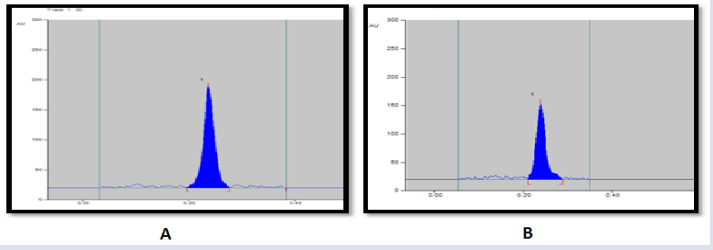

Figure 7: Densitogram of (a) standard ursolic acid and (b) isolated ursolic acid.

Table 1: Linearity of the method

\begin{tabular}{cccc}
\hline Standard & ng/spot & Mean \pm SD & \%RSD \\
\hline \multirow{4}{*}{ UA } & 100 & $1234.3 \pm 15.2695$ & 1.23 \\
& 200 & $1645.9 \pm 8.3321$ & 0.5 \\
& 300 & $1969.1 \pm 24.1119$ & 1.22 \\
& 400 & $2239.5 \pm 16.2333$ & 0.72 \\
& 500 & $2635.96 \pm 29.5585$ & 1.12 \\
& & $\mathrm{Y}=3.397 \mathrm{x}+586.18 ; \mathrm{R}^{2}=0.9954$ & \\
& 100 & $391.7 \pm 5.7515$ & 1.46 \\
& 200 & $663.0 \pm 11.0779$ & 1.65 \\
& 300 & $923.4 \pm 12.9309$ & 1.40 \\
& 400 & $1182.9 \pm 17.4372$ & 1.47 \\
& 500 & $1561.82 \pm 6.5716$ & 0.42 \\
& & $\mathrm{Y}=2.8602 \mathrm{x}-199.5 ; \mathrm{R}^{2}=0.9937$ & \\
\hline
\end{tabular}

Table 2: Repeatability of sample application and measurment

\begin{tabular}{ccccc}
\hline \multirow{2}{*}{ Parameters } & \multicolumn{2}{c}{ UA (300 ng/spot) } & \multicolumn{2}{c}{ OA (300 ng/spot) } \\
\cline { 2 - 5 } & Area \pm SD & RSD & Area \pm SD & RSD \\
\hline Repeatability of measurement & $1989.44 \pm$ & 0.39 & $988.98 \pm$ & 0.99 \\
$(\mathrm{n}=7)$ & 7.85 & & 9.80 & \\
Repeatability of sample & $1981.46 \pm$ & 0.43 & $980.05 \pm$ & 1.14 \\
application ( $\mathrm{n}=7)$ & 8.69 & & 11.21 & \\
\hline
\end{tabular}

sample application of UA and OA are depicted in Table 2 and table 3 respectively.

Accuracy of the method was determined by recovery study from standard mixture of ursolic acid and oleanolic acid at $80 \%, 100 \%$ and
Table 3: Intermediate precision

\begin{tabular}{|c|c|c|c|c|c|}
\hline \multirow[b]{2}{*}{ Standard } & \multirow{2}{*}{$\begin{array}{l}\text { Conc (ng/ } \\
\text { spot) }\end{array}$} & \multicolumn{2}{|c|}{ Intraday precision } & \multicolumn{2}{|c|}{ Interday Precision } \\
\hline & & $\begin{array}{l}\text { AREA MEAN } \\
\pm \text { SD }\end{array}$ & $\%$ RSD & $\begin{array}{l}\text { AREA MEAN } \\
\quad \pm S D\end{array}$ & $\%$ RSD \\
\hline \multirow[t]{3}{*}{ UA } & 300 & $1647.23 \pm 7.85$ & 0.47 & $\begin{array}{c}1647.91 \\
\pm 10.88\end{array}$ & 0.66 \\
\hline & 400 & $1968.40 \pm 9.56$ & 0.49 & $\begin{array}{c}1979.83 \\
\pm 17.85\end{array}$ & 0.90 \\
\hline & 500 & $2231.13 \pm 12.68$ & 0.56 & $\begin{array}{c}2241.80 \\
\pm 24.55\end{array}$ & 1.09 \\
\hline \multirow[t]{3}{*}{$\mathrm{OA}$} & 300 & $667.23 \pm 12.23$ & 1.83 & $663.60 \pm 13.17$ & 1.98 \\
\hline & 400 & $972.70 \pm 10.94$ & 1.12 & $978.66 \pm 11.80$ & 1.20 \\
\hline & 500 & $1186.86 \pm 11.60$ & 0.97 & $1182.30 \pm 22.29$ & 1.88 \\
\hline
\end{tabular}

$120 \%$ level by standard addition method. The results for accuracy are depicted in table 4 .

The other component present in extract did not interfere in the separation and resolution of UA and OA. Comparison of each spectrum scanned at peak start (s), peak apex (m) and peak end (e) positions of bands in samples showed a high degree of correlation (above 0.99 ), confirmed the purity of the bands. This shows specificity of method.

Limit of detection and limit of quantitation was determined by using equation method. The LOD for UA and OA were found to be 21.15 and $6.09 \mathrm{ng} / \mathrm{spot}$, respectively. The LOQ for UA and OA were found to be 64.10 and 18.46 , respectively. Summary of validation parameters are depicted in table 5 .

\section{Quantitation of ursolic acid and oleanolic acid in E. globulus leaves}

Prepared extracts were analysed using developed method. Both DCM and methanolic extract was weighed $10 \mathrm{mg}$ and diluted up to $10 \mathrm{ml}$ $(100 \mu \mathrm{g} / \mathrm{ml})$ and filtered through Whatman filter paper no. 41.A volume of $1 \mathrm{ml}$ filtered solutions were further diluted upto $10 \mathrm{ml}$ with methanol $(100 \mu \mathrm{g} / \mathrm{ml}) .20 \mu \mathrm{l}$ of both extracts solutions were spotted along with mix standard of UA and OA $(20 \mu \mathrm{g} / \mathrm{ml})$. The concentration of UA was found in DCM $(100 \mu \mathrm{g} / \mathrm{ml})(8.72 \% \mathrm{w} / \mathrm{w})$, methanolic $(100 \mu \mathrm{g} / \mathrm{ml}) 4.87 \% \mathrm{w} / \mathrm{w}$ and methanolic $(10,000 \mu \mathrm{g} / \mathrm{ml})(8.49 \% \mathrm{w} / \mathrm{w})$ and the concentration of OA was found in DCM $(100 \mu \mathrm{g} / \mathrm{ml}) 7.31 \% \mathrm{w} / \mathrm{w}$ and methanolic $(10,000$ $\mu \mathrm{g} / \mathrm{ml}) 1.92 \% \mathrm{w} / \mathrm{w}$.

\section{Isolation and identification of ursolic acid from}

\section{E. globulus leaves}

Yield obtained from leaves was $0.06 \%$. Identification of isolated ursolic acid was carried out by peak interpretation of FT-IR and comparison of densitogram and Rf value by HPTLC.

\section{Identification from FT-IR}

FT-IR spectra of isolated UA was compared with FT-IR spectra of standard UA are shown in figure 5 and 6. Peak interpretation is depicted in table 6 .

\section{Identification from HPTLC}

Densitogram of isolated ursolic acid show $R_{f}$ value 0.26 which is nearer to the $\mathrm{R}_{\mathrm{f}}$ value of standard ursolic acid i.e. 0.24 figure 7. Results of FT-IR interpretation and densitogram comparison shows that compound isolated from E. globulus leaves was ursolic acid. 
Table 4: Accuracy of method

\begin{tabular}{cccccc}
\hline Standard & $\begin{array}{c}\text { Amount of standard from } \\
\text { pre-analysed sample (ng/ } \\
\text { spot) }\end{array}$ & $\begin{array}{c}\text { Amount of } \\
\text { standard spiked } \\
\text { (ng/spot) }\end{array}$ & $\begin{array}{c}\text { Total amount } \\
\text { spotted (ng/ } \\
\text { spot) }\end{array}$ & Area & $\begin{array}{c}\text { Mean of spiked amount } \\
\text { recovered } \pm \text { SD (ng/spot) } \\
(\mathbf{n}=3)\end{array}$ \\
\hline UA & 200 & 0 & 200 & 1276.86 & - \\
$\%$ recovery \\
\end{tabular}

Table 5: Summery of validation parameters

\begin{tabular}{|c|c|c|}
\hline Parameters & UA & $\mathrm{OA}$ \\
\hline Linearity range (ng/spot) & $200-600$ & $200-600$ \\
\hline Correlation coefficient $\left(\mathrm{R}^{2}\right)$ & 0.9954 & 0.9937 \\
\hline \multicolumn{3}{|l|}{ Precision } \\
\hline \multicolumn{3}{|l|}{ Repeatability } \\
\hline Repeatability of measurement $(\mathrm{n}=7)$ & 0.39 & 0.99 \\
\hline Repeatability of sample application $(n=7)$ Intermediate precision & 0.43 & 1.14 \\
\hline \multicolumn{3}{|l|}{ Intra-day precision $(\mathrm{n}=3)$} \\
\hline \multirow[t]{2}{*}{ Inter-day precision $(\mathrm{n}=3)$} & $0.47-0.56 \%$ & $0.97-1.83 \%$ \\
\hline & $0.66-1.33 \%$ & $1.20-1.98 \%$ \\
\hline$\%$ Recovery & $100.31 \%-101.50 \%$ & $99.65 \%-100.87 \%$ \\
\hline Limit of Detection (LOD) (ng/spot) & 21.15 & 6.09 \\
\hline Limit of Quantitation (LOQ) (ng/spot) & 64.10 & 18.46 \\
\hline
\end{tabular}

Table 6: Interpretation of FT- IR spectra

\begin{tabular}{cc}
\hline Observed Wave number $\left(\mathrm{cm}^{-1}\right)$ & Indicating group \\
\hline Bonded $-\mathrm{OH}$ & 2929.60 \\
Bond C=O & 1648.2 \\
Aromatic & 1513.91 \\
C $=$ C stretch aromatic & 1455.51 \\
-C-OH deformation vibrations & $1382.56,1313.29$ \\
-C-OH stretching vibrations & $1186.26,1141.60$ \\
9H-C- H out-of-plane bending & 807.49 \\
\hline
\end{tabular}

\section{CONCLUSION}

A validated HPTLC method for separation and determintion of ursolic acid and oleanolic acid in DCM extract of E.globulus has been developed. The HPTLC method is specific, accurate and reproducible and can be used for the separation and simultaneous estimation of the two active components. The developed method offers a cost-effective alternative to the HPLC method for the separation and quantitation of two components. Isolation and identification of isolated compound by HPTLC and FT-IR was carried out. Determination of total triterpenoid present in E. globulus leaf extract was carried out and was found to contain $40-60 \%$ total triterpenoid. Therefore, in order to ensure and improve the thera- peutic benefits, it is necessary to quantify each of the major bioactive components in the leaves of Eucalyptus globulous derived extracts and phytomedicines.

\section{ACKNOWLEDGEMENT}

The authors express their sincere thanks to Dr. Jitendra Singh Yadav from Department of Pharmaceutics for their help.

\section{CONFLICT OF INTEREST}

Authors declare no conflict of interest.

\section{ABBREVIATION USED}

UA: Ursolic acid; OA: oleanolic acid; DCM: dichloromethane; AIDS: acquired immune deficiency syndrome; HIV: Human immunodeficiency virus infection; MECC: micellar electrokinetic capillary chromatography; FTIR: Fourier transform infrared spectroscopy (FTIR); RP-HPLC: Reversed phase High-performance liquid chromatography; HPLC: High-performance liquid chromatography; HPTLC: High performance thin layer chromatography.

\section{REFERENCES}

1. Liu J. Pharmacology of oleanolic acid and ursolic acid. Journal of Ethno pharmacology. 1995;49(2):57-8.

2. Wójciak-Kosior M. Effect of different extraction techniques on quantification of oleanolic and ursolic acid in Lamii albi flos. Industrial Crops and Products. 2013;44:373-7. 
3. Salari M. Antibacterial effects of Eucalyptus globulus leaf extract on pathogenic bacteria isolated from specimens of patients with respiratory tract disorders. Clinical Microbiology and Infection. 2006;12(2):194-6.

4. Domingues R. Eucalyptus globulus biomass residues from pulping industry as a source of high value triterpenic compounds. Industrial Crops and Products. 2010:31(1):65-70.

5. Dzubak P. Pharmacological activities of natural triterpenoids and their therapeutic implications. Natural Product Reports. 2006;23(3):394-411.

6. Laszczyk MN. Pentacyclic triterpenes of the lupane, oleanane and ursane group as tools in cancer therapy. Planta Medica. 2009;75(15):1549-60.

7. Sultana N, Ata A. Oleanolic acid and related derivatives as medicinally important compounds. Journal of Enzyme Inhibition and Medicinal Chemistry. 2008;23(6):739-56.

8. Yogeeswari P, Sriram D. Betulinic acid and its derivatives: a review on their biological properties. Current Medicinal Chemistry. 2005;12(6):657-66.

9. Gupta M. Anti-inflammatory activity of natural products (I) Triterpenoids. European Journal of Pharmacology. 1969;6(1):67-70.

10. Takagi K, Park EH, Kato H.Chemical and Pharmacological Bulletin 1980;28(4):1183-8.

11. DaiY. Anti-inflammatory effect of oleanolic acid. Chinese Journal of Pharmacology and Toxicology. 1989;2:004.

12. Singh G. Anti-inflammatory activity of oleanolic acid in rats and mice. Journal of Pharmacy and Pharmacology. 1992;44(5):456-8.

13. Safayhi $H$, Sailer ER. Anti-inflammatory actions of pentacyclic triterpenes. Planta Medica. 1997;63(6):487-93.

14. Recio MC, Giner RM, Manez S, Gueho J, Julien HR, Hostehmann K, et al. Planta Med. 1995;61(1):9-12

15. Baricevic D, Sosa S, Loggia RD, Tubaro A, Simonovska B, Krasna A, et al.J Ethnophrmarcol. 2001;75:125-32.

16. Neto CC. Cranberry and its phytochemicals: a review of in vitro anticancer studies. The Journal of nutrition. 2007;137(1):186S-93S.

17. Fang $X \mathrm{~J}$. McLaughlin Ursolic acid, a cytotoxic component of the berries of llex verticillata. Fitoterapia. 1990;61(2):176-7.

18. Babalola IT, Shode FO. Ubiquitous ursolic acid: a potential pentacyclic triterpene natural product. Journal of Pharmacognosy and Phyto chemistry. 2013;2(2).

19. Habila J. Triterpenoids from Eucalyptus grandis Hill ex Maiden inhibits platelet aggregation. Afr. J. Microbiology. Res. 2011;5(26):4646-51.

20. KashiwadaY. Anti-AIDS agents. 30. Anti-HIV activity of oleanolic acid, pomolic acid, and structurally related triterpenoids.Journal of Natural Products. 1998, 61(9):1090-5.

21. KashiwadaY. Anti-AIDS agents 38. Anti-HIV activity of 3-O-acyl ursolic acid derivatives. Journal of Natural Products. 2000;63(12):1619-22.

22. Cantrell CL. Antimycobacterial plant terpenoids. Planta Medical. 2001;67(8):685-94

23. Newton SM. A review of antimycobacterial natural products. Phytotherapy Research 2000;14(5):303-22.

24. Kanokmedhakul K. Biological activity of Anthraquinones and Triterpenoids from Prismatomeris fragrans. Journal of Ethnopharmacology. 2005;100(3):284-8.

25. Copp BR. Antimycobacterial natural products. Natural Product Reports. 2003;20(6):535-57

26. Tanachatchairata T, Bremner JB, Chokchaisifi R, Suksamram A. Pharm Bull. 2008;56:194-8.

27. Jaki BU, Franzblau SG, Chadwick LR, Lankin DC, Zhang F, wang Y. J Nat Prod. 2008;71(10):1742-8.

28. He X,Liu RH. J Agric Food Clam. 2007;55:1366-70.

29. Ma X. Studies on the effect of oleanolic acid on experimental liver injury. Yao Xue Xue Bao. Acta Pharmaceutical Sinica. 1982;17(2):93-7.

30. Xu XH. Simultaneous determination of oleanolic acid and ursolic acid by RP-HPLC in the leaves of Eriobotrya japonica Lindl. Journal of Pharmaceutica Analysis. 2012;2(3):238-40

31. Liu H. MECC determination of oleanolic acid and ursolic acid isomers in Ligustrum lucidum Ait. Journal of Pharmaceutical and Biomedical Analysis. 2003;32(3):479-85.
32. SrivastavaP,ChaturvediR. Simultaneous determination and quantification of three pentacyclic triterpenoids-betulinic acid, oleanolic acid, and ursolic acid-in cell cultures of Lantana camara L. In vitro Cellular and Developmental BiologyPlant. 2010;46(6):549-57.

33. Zhao L, LiW, LiY, Xu H, Lv L, Wang X,etal. Journal of chromatographic science. 2015;1-8.

34. GopalV. HPTLC evaluation of oleanolic acid and ursolic acid from the methano extract of Wattakaka volubilis.Journal of Acute Disease. 2014;3(1):59-61.

35. Nowak R, Jciak-kosiorWM, Sowa I, Sokolowska-krzaczek A, PietrzakW, Szczodra A, et al. Acta poloniae pharmaceutica. 2012;70(3):413-8.

36. SongM. Determination of oleanolic acid in human plasma and study of its pharmacokinetics in Chinese healthy male volunteers by HPLC tandem mass spectrometry. Journal of Pharmaceutical and Biomedical Analysis. 2006;40(1):190-6.

37. GbaguidiF. HPLC quantification of two isomeric triterpenic acids isolated from Mitracarpus scaber and antimicrobial activity on Dermatophilus congolensis. Journal of Pharmaceutical and Biomedical Analysis. 2005;39(5):990-5.

38. ChenJ. High-performance liquid chromatographic analysis of bioactive triterpenes in Perilla frutescence. Journal of Pharmaceutical and Biomedical Analysis. 2003:32(6):1175-9.

39. BücheleB. Analysis of pentacyclic triterpenic acids from frankincense gum resins and related phytopharmaceuticals by high-performance liquid chromatography. Identification of lupeolic acid, a novel pentacyclic triterpene. Journal of Chromatography B. 2003;791(1):21-30.

40. ClaudeB. Evaluation of apparent formation constants of pentacyclic triterpene acids complexes with derivatized $\beta$-and $\gamma$-cyclodextrins by reversed phase liquid chromatography. Journal of Chromatography A. 2004;1049(1):37-42.

41. MonteF. Mixture of closely related isomeric triterpenoid derivatives: Separation and purification by reversed-phase high-performance liquid chromatography. Chromatographic. 1997;46(5-6):251-5.

42. LiaoLP. Simultaneous determination of seven triterpenoids and triterpenoid saponins in Folium Ilicis Purpureae by high performance liquid chromatography coupled with evaporative light scattering detection. Journal of separation science. 2005;28(16):2061-6.

43. NeheteJ. Quantitation of oleanolic acid in Achyranthes aspera L. roots and leaves extracts by high-performance thin-layer chromatography. Inter J Pharm Res Dev Online. 2009;2(7).

44. ShailajanS. Estimation of ursolic acid from Urtica dioica L. using validated HPTLC method.Journal of Applied Pharmaceutical Science. 2014;4(5):92.

45. GuptaA. Determination of ursolic acid in fractionated leaf extracts of Ocimum gratissimum Linn and in developed herbal hepatoprotective tablet by HPTLC. Pharmacognosy Journal. 2013;5(4):156-62.

46. GopalV. HPTLC evaluation of oleanolic acid and ursolic acid from the methano extract of Watt Akaka volubilis." Journal of Acute Disease. 2014;3(1):59-61.

47. Wójciak-KosiorM. Effect of different extraction techniques on quantification of oleanolic and ursolic acid in Lamii albi flos. Industrial Crops and Products. 2013;44:373-7.

48. LiuH.MECC determination of oleanolic acid and ursolic acid isomers in Ligustrum lucidum Ait. Journal of Pharmaceutical and Biomedical Analysis. 2003; 32(3):479-85

49. Zhang G.Determination of oleanolic acid and ursolic acid in cornel by cyclodextrinmodified micellar electro kinetic chromatography. Biomedical Chromatography. 2005;19(7):529-32.

50. JorkH.Thin-layer chromatography. Reagents and detection methods. Physical and chemical detection methods: fundamentals, reagents I. Volume 1a: VCH, Weinheim, 1990 (ISBN 3-527-27834-6). xv+ 464 pp. Price DM 148.00." Analytica Chimica Acta. 1990;237:511-2

51. Khandelwal KR, Deore SL. Practical Pharmacognosy Techniques and experiments. Nirali Prakashan, Nineteenth Edition. 2011;206-8.

52. Rajpal, V. Standardization of Botanicals (Testing and Extraction methods of medicinal herbs), Vol. 1, Eastern Publishers, New Delhi, India. 2002. 
GRAPHICAL ABSTRACT

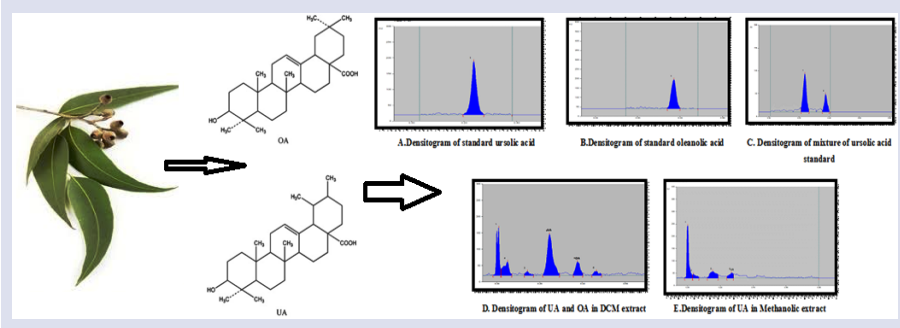

\section{SUMMARY}

- HPTLC method for simultaneously separation of ursolic acid and oleanolic acid in Eucalyptus globulus leaf extract was developed.

- Ursolic acid was also isolated from Eucalyptus globulus leaves.

- The linearity range for UA was found to be $200-600 \mathrm{ng} / \mathrm{spot}$ with correlation coefficient 0.9954 and for OA the linearity range was 200-600 ng/spot with correlation coefficient 0.9937 .

- The method was found to be accurate, precise and specific.

- The developed HPTLC method was successfully validated.

\section{ABOUT AUTHORS}

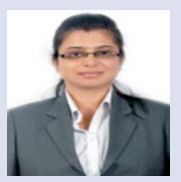

Dr. Arti Gupta: Obtained her Ph.D. in Pharmaceutical science in 2013 from the VNSGU, Gujarat, India. She is currently working as Assistant professor at Maliba Pharmacy college, Uka Tarsadia University, Gujarat, India. Her research is focused on novel herbal, phytopharmacology based investigations, analysis of unexplored natural drugs and HPTLC and formulation development and estimation of herbal formulations.

Cite this article: Gupta A, Maheta P, Chauhan R, Pandey S, Yadav JS, Shah S. Simultaneous quantification of bioactive triterpene acids (ursolic acid and oleanolic acid) in different extracts of Eucalyptus globulus (L) by HPTLC Method. Pharmacog J. 2018;10(1):17985. 